\title{
25 Research Soure \\ Effects of Biofilm Burkholderia Pyrrocinia JK-SH007 On The Colonization And Growth Promotion of Poplar
}

\section{Huanhuan Fu}

Nanjing Forestry University

\section{Weiliang Kong}

Nanjing Forestry University

Feifei Chen

Nanjing Forestry University

Wanhui Liu

Nanjing Forestry University

Qianru Xu

Fuzhou University

Chaoen Wang

Nanjing Forestry University

Xueqi Fang

Nanjing Forestry University

Jianren Ye ( $\sim$ jrye@njfu.edu.cn )

Nanjing Forestry University

Original article

Keywords: Burkholderia pyrrociniaJK-SH007, Biofilm, Colonization, Promoting Health, Biocontrol

Posted Date: November 12th, 2021

DOI: https://doi.org/10.21203/rs.3.rs-1031114/v1

License: (c) (i) This work is licensed under a Creative Commons Attribution 4.0 International License.

Read Full License 


\section{Abstract}

Burkholderia pyrrocinia JK-SH007 is a high-potential biological control strain. We changed the composition of medium during the fermentation of JK-SH007 cells and induced these cells to form a biofilm. In this experiment, we deeply studied the biofilm physical and chemical properties. The new fermentation process improves the colonization ability of JK-SH007 and promotes poplar growth. In addition, the biofilm bacterial concentration reached $10^{10} \mathrm{CFU} / \mathrm{mL}$, the cell dry weight increased over that of a control by 3-10-fold, there was increased environmental stress resistance and IAA secretion, and progeny cells retained resistance to adverse environments. The new biofilm cells were applied to poplar. The JK-SH007 colonization ability was improved in the biofilm, and some bacteria existed as biofilms (cell clusters) in poplar, which would promote forming a dominant niche. Biofilm JK-SH007 has an increased affinity for poplar during colonization and promotes poplar growth under hydroponic conditions, proving the reliability of the new morphology for treating poplar ulcer disease. This work further provides a theoretical basis for commercially producing JK-SH007.

\section{Introduction}

Biocontrol strains use microbes instead of chemical agents and inhibit the growth of pathogenic fungi through interactions between organisms, thereby achieving therapeutic effects on plant diseases. There are many naturally occurring antagonistic bacteria, and they play important roles in the sustainable development of nature. Some of them have been isolated by humans and reinoculated on plants to enhance plant growth health and resistance (Masoud A et al. 2011; Fernando et al. 2009; Clara Pliego at al. 2010; Riahi, $\mathrm{H}$ et al. 2012). On the one hand, compared with chemical control, biological control does not pollute the environment, leaves no pesticide residues, and exhibits no resistance(MinJia at al. 2017; Grzegorczyk et al.2016). On the other hand, biocontrol bacteria can also promote plant growth (Ester Simonetti et al. 2017). The ability to promote growth depends on the metabolism of biocontrol bacteria. The relevant processes include dissolving the insoluble mineral potassium phosphate in the soil, improving the soil environment, forming nutrients that are easily absorbed by plants, and using bacteria to produce hormones, enzymes and other substances that promote plant growth during metabolic processes to accelerate plant cell growth and increase plant chlorophyll content (Wenyan et al.2019).

Biocontrol bacteria are often made into biological fertilizers and applied to plants, but colonization is the key to whether they can perform their functions (Nunes-Alves et al.2014;Laura et al.2020) In the microbial environment around the plant, most bacteria colonize as biofilms (Maude et al.2020). A biofilm is a community formed by the aggregation of microorganisms. It involves the metabolism of microorganisms and changes in bacteria between forms found in nature, planktonic and biofilms (Sauer $\mathrm{K}$ et al.2002; Schembri et al. 2003). Although the structure of a single bacterium itself has not changed significantly within biofilms, it is combined into a group connected by extracellular polysaccharides and other media. The largest change from the planktonic state is an enhancement of the chemical or biological factors or tolerance to physical factors. (Merle E Olson et al.2002; Barbara et al. 2015). Biofilm is a protection mode of bacteria themselves, especially in complex field environments. Biofilms are particularly important for 
the competitive status of species. In terms of biological control, Ji et al. found that the formation of a biofilm by Bacillus is beneficial to controlling bacterial wilt of various host plants (Xianling et al.2008). Zhao found that $\beta$-glucan can promote the formation of Cryptococcus podzolica biofilms and improve the biological control ability of Penicillium pears (YunWang et al. 2018). Dongling et al. found that Pseudomonas putida has a better control effect on tomato bacterial wilt as a biofilm than as planktonic cells (Dongling Sun et al.2017).

Burkholderia pyrrocinia JK-SH007 belongs to the onion Burkholderia genotype IX and is used as a biocontrol agent in the prevention and treatment of poplar ulcer disease in China. According to reports, JK-SH007 is applied as a biofertilizer to the soil environment of poplar roots. It not only improves soil growth and biodiversity and poses little threat to indigenous microorganisms in the environment but also promotes the growth of poplars and increases the resistance of poplars to pathogenic fungi, reducing the occurrence of poplar ulcer disease (Ren et al.2011; Ren et al.2016). In practical applications, due to the stabilization of the environment itself and the application of JK-SH007 in a complex and changing natural environment, the number of poplars that can be successfully colonized reaches the highest value in a short period of time, then decreases with time, and eventually stable low numbers even become zero (Michaela, C.et al.2014). This is because its own phytoplankton morphology results in rapid growth, so the phytoplankton morphology is the most common pattern in the growth history of the bacterium. However, with the continuous coevolution of microorganisms and hosts in this nature, most pathogens have evolved a set of protective modes: biofilms to improve their tolerance and pathogenicity. As a result, when JK-SH007 is commonly used for poplar biocontrol inoculation, repeated inoculations are required over time, which severely restricts the marketization of the bacteria. In this paper, the related functions of JK-SH007 in a biofilm morphology were analyzed by using cell culture, molecular biology, and plant culture. Studying whether adding nutrients to the medium can strengthen bacterial resistance and promote colonization in poplar allows bacteria to be better applied to the prevention and treatment of poplar ulcer disease.

\section{Materials And Method}

\section{Microorganism}

Burkholderia pyrrocinia JK-SH007 was isolated from poplar and was deposited the Chinese Type Culture Collection (CCTCC: M209028).

\section{The effect of nutrient source on the growth threshold of JK- $\mathrm{SHOO7}$}

The purpose of this experiment was to determine the upper limit of JK-SH007 cell density in the fermentation stage as a biofilm. The control group used TSB medium ( $15 \mathrm{~g} / \mathrm{L}$ tryptone, $5 \mathrm{~g} / \mathrm{L}$ soya peptone, and $5 \mathrm{~g} / \mathrm{L} \mathrm{NaCl}$ ), and the experimental group contained two additional nutrients in TSB medium: 
$\mathrm{MgSO}_{4} 7 \mathrm{H}_{2} \mathrm{O}$ and glycerol. The final concentration of $\mathrm{MgSO}_{4} 7 \mathrm{H}_{2} \mathrm{O}$ was $25 \mathrm{mM}$, and the ratio of glycerol to TSB medium was $1 \%$. For a related scheme, refer to the article by Wiyono et al.( Wiyono, S et al.2008).

Uncontaminated JK-SH007 glycerol bacteria were removed from a $-80{ }^{\circ} \mathrm{C}$ refrigerator, and single colonies were cultivated on LB solid medium (Gideon et al.2016). A sterile toothpick was used to pick a single colony and immerse it in LB liquid medium. It was activated at $28^{\circ} \mathrm{C}$ and $180 \mathrm{r} / \mathrm{min}$ in a shaker, and the culture was shaken for $24 \mathrm{~h}$ to obtain a bacterial suspension.

Then, $20 \mathrm{~mL}$ of test medium was added to a $50 \mathrm{~mL}$ Erlenmeyer flask, and the bacterial suspension obtained in the early stage was inoculated into the test medium at a concentration of $1 \%$. The culture conditions were $28{ }^{\circ} \mathrm{C}$ and $180 \mathrm{r} / \mathrm{min}$. The incubation time was $60 \mathrm{~h}$, and three replicates were set for each treatment group.

The growth of JK-SH007 was evaluated by an ultraviolet spectrophotometer: a $48 \mathrm{~h}$ bacterial suspension was centrifuged to remove the medium and metabolic products to obtain cells, sterile water was added, and the mixture was stirred to obtain a resuspended solution. Ultraviolet spectrophotometry was used to measure the absorbance of the resuspended solution at $600 \mathrm{~nm}$. According to a growth standard curve, the cell density was obtained.

The resuspended solution was centrifuged again, the supernatant was discarded, the cell pellet was placed in an oven and dried at $70{ }^{\circ} \mathrm{C}$, and the dry weight of the cells was determined (Hoang-Minh Nguyen et al.2019).

\section{Determination of resistance to environmental stress in biofilms}

The stress resistance of JK-SH007 biofilm cells was explored by changing the medium composition, culture conditions and temperature, alkali, and heavy metal stress conditions in an artificial culture. An indepth study of bacterial growth and cells under different levels of environmental stress was performed. The control group used TSB medium as the main component, and the treatment group had $\mathrm{Mg}^{2+}$ and glycerin added to the TSB medium.

The preparation of the activated bacterial suspension was as described above.

Temperature stress tests: $20 \mathrm{~mL}$ of test medium was added to $50 \mathrm{~mL}$ Erlenmeyer flasks, and the bacterial suspension obtained in the previous stage was inoculated at $1 \%$ concentration in the test medium. For low temperature stress, the culture temperature was set to $4{ }^{\circ} \mathrm{C}$, and the culture was kept in the dark. The absorbance was determined at $600 \mathrm{~nm}$ every $24 \mathrm{~h}$ for 7 consecutive days; for high temperature stress, the culture temperature was set to $37^{\circ} \mathrm{C}$, and the shaking speed was set to $180 \mathrm{r} / \mathrm{min}$. After the shaking culture, the absorbance of the bacterial solution at $600 \mathrm{~nm}$ was measured after $48 \mathrm{~h}$.

Alkali stress tests: $20 \mathrm{~mL}$ of test medium was added to a $50 \mathrm{~mL}$ conical flask, the $\mathrm{pH}$ of the test medium was adjusted to 9 , and the activated bacterial suspension was inoculated at $1 \%$. Since $28{ }^{\circ} \mathrm{C}$ is a suitable 
temperature for the growth of $\mathrm{JK}-\mathrm{SH} 007$, the growth of $\mathrm{JK}-\mathrm{SH} 007$ in the two forms was almost the same. To reduce the influence of temperature conditions on the experimental results, this experiment used a cultivation temperature of $28{ }^{\circ} \mathrm{C}$ and a rotation speed of $180 \mathrm{r} / \mathrm{min}$ in a shake culture. Forty-eight hours later, the absorbance of the bacterial solution was measured at $600 \mathrm{~nm}$.

Heavy metal stress tests: $20 \mathrm{~mL}$ of test medium was added to a $50 \mathrm{~mL}$ conical flask, and $\mathrm{CuSO}_{4} \cdot 5 \mathrm{H}_{2} \mathrm{O}$ was added to the test medium to ensure that the final concentration was $70 \mathrm{mM}$. The activated bacterial suspension was inoculated at $1 \%$. In this experiment, the culture temperature was set at $28{ }^{\circ} \mathrm{C}$, and the rotation speed was $180 \mathrm{r} / \mathrm{min}$. The absorbance of the bacterial solution was measured at $600 \mathrm{~nm}$ after $48 \mathrm{~h}$.

Three repetitions were performed for each treatment group.

\section{Effects of nutritional source on the secretion of IAA by JK- $\mathrm{SHOO7}$}

In this experiment, we compared the content of indole-3-acetic acid (IAA) in the metabolites of JK-SH007 in the planktonic and biofilm states. The control group used TSB medium; the treatment group also had $\mathrm{Mg}^{2+}$ and glycerol in TSB medium to ensure the formation of biofilms. The culture conditions were dark at $37^{\circ} \mathrm{C}$ and $180 \mathrm{r} / \mathrm{min}$, and the culture time was $48 \mathrm{~h}$. Afterwards, the bacterial suspension was centrifuged to remove the bacteria, and the ability of the two forms to produce IAA was determined by Salkowski colorimetry (Zhou et al.2017).

Three repetitions were performed for each treatment group.

\section{Determination of salt resistance of JK-SH007 progeny cells}

Biofilms of JK-SH007 are produced by the change in fermentation conditions; in actual application, the environment does not have the conditions for biofilm formation. The purpose of this experiment is to study the bacteria in the biofilm morphology, out of the environment, and to determine whether progeny cells retain their stress resistance.

The test medium was prepared as described above, and a suspension of planktonic JK-SH007 cells and a biofilm suspension were obtained. Through centrifugation, the supernatant was discarded, the cells were resuspended, and the $\mathrm{OD}_{600}$ values of the resuspension solutions were adjusted to be the same.

LB media were made with different $\mathrm{NaCl}$ concentrations $(\mathrm{g} / 100 \mathrm{~mL}): 1,1.2,1.4,1.6,1.8,2.0,2.2,2.4,2.6$, $2.8,3.0,3.2,3.4,3.6,3.8,4.0,4.5,5.0$, and 6.0 . Then, $1 \%$ of the adjusted resuspension was inoculated into the different media and cultivated at $28{ }^{\circ} \mathrm{C}$ and $180 \mathrm{r} / \mathrm{min}$ in a shaker. After $48 \mathrm{~h}$, the absorbance of the bacterial solution at $600 \mathrm{~nm}$ was measured.

Three repetitions were performed for each treatment group. 


\section{Electron microscopy observation after colonization of poplar with JK-SH007}

JK-SH007 morphological observation was performed in the following manner. TSB medium was used to prepare a suspension of $\mathrm{JK}-\mathrm{SH} 007$ planktonic bacteria. $\mathrm{Mg}^{2+}$ and glycerin were added to the TSB medium to prepare the JK-SH007 suspension as a biofilm. The bacterial suspension was added to 12well cell culture plates, and a sterile cover glass was placed vertically in each well. They were sealed and allowed to stand for 6 days. After the biofilms matured and stabilized, the coverslip was removed, a scalpel was used to scrape the bacteria, and the bacteria were placed in a phosphate $(0.1 \mathrm{M})$ glutaraldehyde (2.5\%) buffer solution and fixed. After that, the sample was cleaned with distilled water and ethanol, dehydrated, placed in professional equipment for gold spraying, and finally observed using a field emission scanning electron microscope.

The colonization of poplar by JK-SH007 as a function of morphology was characterized in the following manner. TSB medium was used to prepare a suspension of JK-SH007 planktonic bacteria, and $\mathrm{Mg}^{2+}$ and glycerin were added to the TSB medium to prepare a JK-SH007 biofilm suspension. Then, sterile poplar seedlings were inoculated with $2 \mathrm{~mL}$ of bacterial suspension. After 7 days, leaf tissue was collected from each sample, and the collected poplar tissue was placed into phosphate $(0.1 \mathrm{M})$ glutaraldehyde $(2.5 \%)$. In this buffer, electron microscopy observations were performed as above.

\section{Effect of the biofilm morphology on Populus colonization by JK-SH0O7}

TSB medium was used to prepare a bacterial suspension of planktonic JK-SH007 bacteria, and $\mathrm{Mg}^{2+}$ and glycerin were added to the TSB medium to prepare a biofilm JK-SH007 suspension. A centrifuge and distilled water were used to adjust the OD600 of the bacterial suspension to identical values, sterile poplar seedlings were inoculated with $2 \mathrm{~mL}$ of the resuspended solution, and the entire poplar sterile seedlings were extracted at $7,14,21,28$, and 35 days, They were weighed and put in a dry pot, and a relative volume of distilled water according to weight was added. They were ground, and tissue fluid was collected and poured into a $2 \mathrm{~mL}$ centrifuge tube, where it was allowed to stand for 15 minutes. The precipitate was discarded, the tissue fluid was diluted to a range of concentrations, and the number of JKsamples were determined by the coating method The relative number of JK-SH007 cells that had colonized poplar was determined.

\section{Effect of the biofilm morphology on the compatibility of JK- SH007 and colonized poplar}

In this experiment, JK-SH007 colonized poplar as a biofilm, and its metabolic products changed the poplar affinity. Young and sterile healthy seedlings and TSB medium were chosen to prepare fermentation broth with JK-SH007 planktonic bacteria, while $\mathrm{Mg}^{2+}$ and glycerol were added to TSB medium to prepare fermentation broth for JK-SH007 biofilms. Samples were centrifuged at 10,000 rpm 
for 2 minutes. The precipitate was discarded, a sterile fermentation broth (containing bacterial metabolites) of JK-SH007 was prepared, and sterile poplar seedlings were inoculated with the metabolic products in excess. The seedlings were placed in a light incubator and grown in a simulated natural environment, and the growth of poplar seedlings was monitored.

Ten repetitions were performed for each treatment group.

\section{JK-SH007 promotes the growth of poplar}

In a study by Min et al., JK-SH007 had a significant growth-promoting effect and was shown to secrete IAA (MIN Lijing et al.2019), enzymes and siderophores that can promote plant growth. Due to the different amounts of metabolites secreted in biofilms, this experiment investigated the effects of nutrient addition on the growth-promoting ability of JK-SH007.

A fermentation broth was prepared for planktonic JK-SH007 bacteria using TSB medium, while $\mathrm{Mg}^{2+}$ and glycerin were added to TSB medium to prepare a fermentation broth for JK-SH007 biofilms. The fermentation conditions were $37^{\circ} \mathrm{C}$ and shaking at $180 \mathrm{r} / \mathrm{min}$ in the dark for $48 \mathrm{~h}$.

Annual poplar seedlings were selected, $15 \mathrm{~cm}$ cuttings were cut, and cutting seedlings of the same size, individual biomass, tree height and crown width were selected. They were robust and free from diseases and insect pests for hydroponic experiments (Xu et al.2015). The Hoagland nutrient solution for the hydroponic system was chosen, the $\mathrm{pH}$ of the hydroponic system was adjusted to 7.0 with $\mathrm{NaOH}$ solution, and the volume of each bottle was $300 \mathrm{~mL}$ to ensure a constant volume of hydroponic solution. A positive control group was set up (planktonic JK-SH007), a negative control group had distilled water, a treatment group had JK-SH007 biofilm, and there were three other working groups, with each treatment having 10 strains. The nutrient solution was changed every 10 days, and after the nutrient solution was changed twice, each plant was treated with $3 \mathrm{~mL}$ of bacterial solution every 10 days per bottle for continuous treatment for 40 days. The tender leaves were selected, carefully preserved and brought back to the laboratory to measure the leaf area (Wangxiang et al.2017).

\section{Statistical Analysis}

The data were analyzed by analysis of variance and the Duncan multiple comparison test with SPSS 22.0 software (IBM Inc., Armonk, NY, USA), and the standard errors of all mean values were calculated ( $p$ $<0.05)$.

\section{Result}

\section{Effects of nutrient sources on the JK-SH007 growth threshold and IAA secretion}

The results for JK-SH007 secreting IAA are shown in Figure 1A. The nutritional conditions were changed to induce JK-SH007 to form a biofilm. The IAA content in the metabolites was $1.1563 \mu \mathrm{g} / \mathrm{mL}$, which was an increase of $0.2001 \mu \mathrm{g} / \mathrm{mL}$ over that of the planktonic form. IAA is a hormone that promotes plant growth, and changes in the content of metabolized IAA will impact the ability of JK-SH007 to promote 
growth as a biocontrol agent on poplar. At suitable temperatures, JK-SH007 grows rapidly in a closed medium, and the number of cells reaches a growth threshold when nutrients are depleted. In TSB medium, JK-SH007 grew and metabolized in planktonic mode and grew after $48 \mathrm{~h}$. The cell density reached its highest value, the $\mathrm{OD}_{600}$ value was 2.5559 , and the dry cell weight was measured after drying to be $0.035 \mathrm{~g}$; in the treatment group with $\mathrm{Mg}^{2+}$ and glycerol added to TSB medium, JK-SH007 grew and metabolized as a biofilm. After $48 \mathrm{~h}$, the cell density reached the highest value, and the $\mathrm{OD}_{600}$ value was 2.7156. The dry cell weight was $0.192 \mathrm{~g}$, which was 3-10 times higher than that of the planktonic group, and the number of cells was significantly increased (Figures 1B, 2A).

\section{Effects of the biofilm state on the growth of JK-SH007 under different stresses}

Temperature stress studies indicate that $\mathrm{JK}$-SH007 in the biofilm group had significant resistance to temperature stress. Under high temperature stress, the $\mathrm{OD}_{600}$ value was 2.66 , while the cell concentration of the planktonic bacteria group was only 1.912; under low temperature stress, both groups of bacteria grew poorly, but the OD value of the biofilm group was slightly higher than that of the planktonic group (Figure 2B).

The results of the $\mathrm{pH}$ stress studies are shown in Figure 2C. After $\mathrm{Mg}^{2+}$ and glycerin were added, the adaptability of $\mathrm{JK}-\mathrm{SH} 007$ to an alkaline environment was significantly improved, and the measured $\mathrm{OD}_{600}$ value was 2.773; without these two nutrients, JK-SH007 grew in planktonic mode, and in TSB medium at $\mathrm{pH} 9$, its growth was significantly reduced. The cell concentration was measured after $48 \mathrm{~h}$, and the $\mathrm{OD}_{600}$ value was only 1.859 .

At a high concentration of $\mathrm{Cu}^{2+}$, the growth of planktonic JK-SH007 was inhibited. After $48 \mathrm{~h}$ of shaking culture, the $\mathrm{OD}_{600}$ value of the fermentation broth was 2.017 , which was less than those of the high temperature stress and alkali sexual stress groups, while in the treatment group, even when grown at a $\mathrm{Cu}^{2+}$ concentration as high as $70 \mathrm{mM}$, JK-SH007 still had high growth. After $48 \mathrm{~h}$ of shaking culture, the OD600 of the fermentation broth was 2.694 (Figure 2D).

\section{Determination of salt resistance of JK-SH007 progeny cells}

The previous experimental results show that changing the nutrient source during fermentation and inducing JK-SH007 to form a biofilm will increase its potential use in all aspects. The progeny cells from the two forms of JK-SH007 should respond to high concentrations of $\mathrm{NaCl}$. Experimental results showed that the progeny of planktonic JK-SH007 reduced their growth when the $\mathrm{NaCl}$ concentration in the fermentation broth reached $2.6 \mathrm{~g} / 100 \mathrm{~mL}$. The growth limit and increasing cell density will cause the cells not to grow. After $\mathrm{JK}-\mathrm{SH} 007$ is subjected to $\mathrm{Mg}^{2+}$ and glycerol, it grows and metabolizes as a biofilm. Its progeny cells grow in environments without $\mathrm{Mg}^{2+}$ and glycerol, and their strong resistance is retained. When the $\mathrm{NaCl}$ concentration reached $4 \mathrm{~g} / 100 \mathrm{~mL}$, the growth of cells began to be inhibited, and the growth of JK-SH007 stopped only when the concentration reached $6 \mathrm{~g} / 100 \mathrm{~mL}$ (Figure 3A). 


\section{Effect of the biofilm morphology on Populus colonization by JK-SH007}

JK-SH007 colonization in poplars can reflect the underlying colonization rules, and both planktonic and biofilm colonization showed a trend of rising first, then falling, and then stabilizing. The cells entered a relatively stable period after 35 days. However, the colonization number for biofilm JK-SH007 was higher than that for planktonic cells. The dynamics of biofilm colonization in poplars are shown in Figure 3B. The relative colonization number on day 7 was $9.08 \log _{10} \mathrm{CFU}$, which slowly decreased to $7.19 \log _{10} \mathrm{CFU}$ in 28 days and finally became $8.11 \log _{10}$ CFU after 35 days. The colonization number for poplars with planktonic cells was $8.6427 \log _{10} \mathrm{CFU}$ on the 7 th day, and it decreased slowly. At 28 days, it reached a minimum value of $7.11 \log 10 \mathrm{CFU}$, and then it increased to $7.60 \log 10 \mathrm{CFU}$ on the 35 th day.

\section{Electron microscopy observation after colonization of popular by JK-SH007}

Electron microscopy showed that JK-SH007 grows in TSB medium with or without $\mathrm{Mg}^{2+}$ and glycerol. The results are shown in Figure 4. Normally grown JK-SH007 exhibits obvious colony division, and bacteria survive in a single mode of typical planktonic growth (Figure 4A, 4B); JK-SH007 grows on TSB medium supplemented with $\mathrm{Mg}^{2+}$ and glycerol, and the colonies converge together to form an organized three-dimensional community. It was found under an electron microscope at 30,000x magnification that a single bacterial cell appears in a layer of material, which is a typical biofilm structure (Figure 4C, 4D).

We observed JK-SH007 colonization on poplar. Planktonic cells were single bacteria scattered on the leaf tissue of poplar (Figure 5A, 5B), while for biofilm JK-SH007, some bacteria converge together to form cell clusters at 10,000 $\times$ magnification. The cell clusters have the typical three-dimensional structure of biofilms (Figure 5C, 5D). This morphology can improve the interspecies communication of bacteria and cope with external adverse conditions. It is worth noting that although JK-SH007 gathers in parts of the poplar body, it does not affect the growth of the poplar.

\section{Effect of the biofilm morphology on the compatibility of JK-SH007 and colonized poplar}

The metabolites of JK-SH007 were inoculated into poplar seedlings to study the affinity of poplar to JKSH007. Normally cultured JK-SH007 metabolites were inoculated into poplar tissue culture seedlings. After growing for a period of time, the leaves became green, and the entire plant turned white and eventually died. Although some leaves of the seedlings turned red, they were not lethal, and after a period of adaptation, the growth improved, and the symptoms were alleviated. Through the influence of metabolites on poplar, it is proven that the biofilms have a higher affinity for poplar than the planktonic cells do during inoculation (Figure 6).

\section{JK-SH007 promotes the growth of poplar}

In this experiment, we performed a hydroponic test on poplar to examine the correlation between JKSH007 growth promotion and the cell forms. Figure 7 shows that the both addition and absence of $\mathrm{Mg}^{2+}$ and glycerol in the culture medium led to JK-SH007 having a significant effect on the promotion of poplar 
germination. In the water control group (Figure 7-A), there was less germination in the front cuttings of poplars and sparse branches and leaves, and some leaves were curled and had an increased mortality rate. The germination effect of the planktonic group was better than that of the control group. The number of plants increased by $75 \%$, the leaf area increased by $64 \%$, and the mortality rate decreased by $10 \%$ (Figure 7-B). The shoot growth in the biofilm group was significantly improved compared with the growth in the planktonic group, the number of leafed plants increased by $100 \%$, the leaf area increased by $300 \%$, and the mortality rate decreased by $20 \%$ (Figure $7-C$ ). The data show that the performance of biofilms in promoting growth is greater than the performance of planktonic bacteria in promoting growth.

\section{Discussion}

We performed relevant functional tests on JK-SH007 biofilms, and the results showed that the population density increased compared to that of planktonic bacteria. We speculate that the formation of biofilms promotes the uptake of nutrients and upregulates the expression of related gene (Michaela et al.2014) resulting in increased cell viability and cell aggregation, which leads to more efficient use of space. The cell growth threshold is increased for biofilm cells. Rosier reported that Pseudomonas aeruginosa increased its cell concentration and diversity of metabolites under the formation of biofilms (Carl $L$ et al.2019). Saheli et al. found that when D-tryptophan (D-TRP) was used to inhibit the formation of Pseudomonas biofilms, the cell adhesion of Pseudomonas decreased, and the cell concentration also decreased significantly (Ghosh, $S$ et al.2019). This experiment proves that increasing the concentration of bacteria to promote $\mathrm{JK}$-SH007 biofilm formation without relying on expensive nutrients is feasibly. This provides a new theoretical basis for fermentation conditions for bacterial market application.

According to the results of the stress resistance experiment, biofilms increase JK-SH007 stress resistance to adverse environments. For example, in an environment with a high concentration of heavy metals, the growth of biofilm JK-SH007 was hardly affected. Biofilms are a mechanism of bacterial resistance (Jolivet-Gougeon et al.2014), which leads to weakening of the host's ability to cope with pathogen invasion (Nargis et al. 2017). Similar to the results of this experimental study, Zhang et al. used cell separation methods to show that biofilms produced by Bradyrhizobium cells in tap water exhibit increased resistance to antibiotics (Junpeng Zhang et al.2018).

During the growth of JK-SH007, the composition of the culture medium was changed. We observed differences in cells through an electron microscope and found that under the stimulation of two nutrients, the surfaces of the bacteria were covered with a layer of polysaccharides. There are obvious biological metabolic pathways in the community, which formed a highly stable and organized group living together. This explains the formation of biofilms, and Gao et al. observed the same results using an electron microscope (Tantan Gao et al.2015). When JK-SH007 was applied as a biofilm to sterile poplar, a cell cluster structure was found on the leaves. Generally, the formation of cell clusters produces a large amount of metabolites in a certain part of the host body, which will not be conducive to the host's growth. For biofilm JK-SH007, it may be that the cells are wrapped by exosporium, which causes regular growth and metabolism among species (Abdelkarim et al.2017). As a result, the impact on the poplar itself 
becomes low. Through an analysis of the colonization number at different times, the colonization number of biofilm JK-SH007 inoculated in poplar trees was higher than that of planktonic bacteria in each time period. In the wild, high-density colonization of biocontrol strains in the surrounding environment of the host can effectively compete with other pathogens for space and nutrients, which is considered to be an important biocontrol mechanism (Jia Liu et al.2013). In addition, the affinity experiment confirmed that even if a group of cells gathered together for growth and metabolism, it did not have an adverse effect on the poplar, and due to changes in metabolites, it actually increased the affinity for the poplar. This indicates that JK-SH007 adopting the biofilm morphology increases its colonization ability and affinity for the host, which will help it occupy a dominant niche in the complex microbial community around the host. In a similar study, some scholars used Paraburkholderia tropica to colonize barley to increase grain production (García et al.2019). Klein et al. also found that biofilm formation by biocontrol strains can improve the biocontrol effect against pathogens (Klein et al.2018; Theresa Klein et al.2016; Jing Xia et al.2018). JK-SH007, as a high-potential biocontrol bacterium, grows under normal conditions, and it has difficulty forming biofilm. The reason may be that it has a high expression of movement-related genes during the growth stage, and it has difficulty clustering. When applied in the wild environment, planktonic JK-SH007 has much lower vitality than the biofilm JK-SH007, which will affect its biological control effect. This study has a good result for this problem. This experiment provided the possibility that biofilm JK-SH007 could be used as a biological agent in the field.

IAA is a hormone used to stimulate plant growth. It can promote the growth and development of plants within a certain concentration range. IAA produced by the metabolism of beneficial bacteria generally promotes the growth of plant organs ( $\mathrm{Li}$ Xu et al.2015). JK-SH007, as a beneficial antibacterial, can also secrete IAA itself (Wan-Hui,Liu et al.2019). We confirmed through experiments that as a biofilm, its metabolic IAA content increased. The subsequent growth-promoting poplar hydroponic experiments also confirmed that $\mathrm{JK}$-SH007 cultured with $\mathrm{Mg}^{2+}$ and glycerin in the nutrient source promoted the germination and growth of plants. The disadvantage is that this experiment was conducted under hydroponic conditions, which is more conducive to the metabolism of bacteria than soil is, i.e., in the wild environment. Can JK-SH007 have the same growth promotion in the soil environment? The effect will be the focus of future research.

These experimental results show the importance of adding nutrients during the fermentation of JK$\mathrm{SH} 007$ and its possible use to control poplar ulcer disease. The addition of nutrients can change the morphology of JK-SH007 biofilms, and these experiments proved the advantages of biofilms in terms of stress resistance, affinity, and growth promotion. In China, poplar is used as a shelterbelt for large-scale planting, and a single variety causes a large-scale outbreak of poplar ulcer disease during drought (Chen et al.2012). The application of JK-SH007 as a biological fertilizer in the field has become an important topic. This study is the first report that adding nutrients during the fermentation stage changes its metabolism to make it more effective in performing related functions around the poplar. When JK-SH007 is commercialized as a biological fertilizer, this study can be used as an important reference. In follow-up 
research, the potential biological control ability of biofilm JK-SH007 after poplar colonization can be considered.

\section{Declarations}

\section{Ethics approval and consent to participate}

All the authors listed have approved the present submitted version. And does not involve ethical issues.

\section{Consent for publication}

All the authors are agree to publish.

\section{Availability of data and materials}

All the data and materials have been provided in main manuscript.

\section{Competing interests}

I would like to declare on behalf of my co-authors that any figure or text taken from another paper is clearly indicated with the full source and permission of the authors of said source. Besides, our manuscript has not been published previously, and not under consideration for publication elsewhere, in whole or in part.

\section{Funding}

This work was supported by the agricultural Independent Innovation Project of Jiangsu Province (CX [16] 1005) and the Priority Academic Program Development of the jiangsu Higher Education Institutions (PAPD).

\section{Author Contributions}

HF performed and studied most of the experiments in manuscripts and Analyzed experimental data and drafted linked content of the manuscript. FC and WHL and CEW and XQF and QRX was involved in the planning and execution of the research work; analysis and interpretation of the data; WLK participated in the grammar and experimental planning of the manuscript; JRY as research supervisor of HF was involved in planning of research work; analysis and interpretation of data; All the authors agreed to be accountable for all aspects of the work in ensuring that questions related to the accuracy or integrity of any part of the work are appropriately investigated and resolved. All authors read and approved the final manuscript.

\section{Acknowledgments}

We are grateful to Professor Jianren Ye for guiding for my research. 


\section{References}

1. Abdelkarim Mahdhi,Nadia Leban,Ibtissem Chakroun,Mohamed Aymen Chaouch,Jawhar Hafsa,Kais Fdhila,Kacem Mahdouani,Hatem Majdoub.,(2017)Extracellular polysaccharide derived from potential probiotic strain with antioxidant and antibacterial activities as a prebiotic agent to control pathogenic bacterial biofilm formation. Microbial Pathogenesis ,p. S0882401016305174.

2. Barbara, Kanegsberg, Stephen,Lyon, Ed, \& Kanegsberg.(2015)An introduction to microbial biofilms.Controlled Environments Magazine.

3. Ben Abdallah, D., O. Frikha-Gargouri and S. Tounsi, Rizhospheric competence,(2018) plant growth promotion and biocontrol efficacy of Bacillus amyloliquefaciens subsp. plantarum strain 32a. Biological Control: p. S1049964418300422.

4. Carl L. Rosier,Estella A. Atekwana, Gamal Abdel Aal,Marianna A. Patrauchan. $8(2019)$ Cell concentrations and metabolites enhance the SIP response to biofilm matrix components. Journal of Applied Geophysics, 160: p. 183-194.

5. Chen, SQ,Zhong ZL, Li HT, Li J, Chu XR, (2012,) Research progress on chemical constituents and pharmacological effects of poplar bud extracts. Chinese Journal of Clinical Pharmacology \& Therapeutics,17(11):1302-1306.(in Chinese)

6. Clara Pliego,Cayo Ramos,Antonio de Vicente,Francisco M., (2012)CazorlaScreening for candidate bacterial biocontrol agents against soilborne fungal plant pathogens. Plant \& Soil, Vol.340 (1-2), pp.505-520

7. Dongling Sun,Tao Zhuo,Xun Hu,Xiaojing Fan,Huasong Zou,(2017)Identification of a Pseudomonas putida as biocontrol agent for tomato bacterial wilt disease. Biological Control, ,114,45-50

8. Ester Simonetti,Irma N. Roberts,Marcela S.Montecchia,Flavio H.Gutierrez-Boem,Federico M. Gomez,Jimena A. Ruiz, (2017) A novel Burkholderia ambifaria strain able to degrade the mycotoxin fusaric acid and to inhibit Fusarium spp. growth. Microbiological Research , 206: p. 50.

9. Fernando Haddad,Luiz A. Maffia,Eduardo S.G. Mizubuti,Hudson Teixeira, (2009)Biological control of coffee rust by antagonistic bacteria under field conditions in Brazil. Biological Controlष49(2): p. 0119.

10. García, Julia Elena Puente, Mariana Laura Galar, María Lina Prieto, Claudia Inés Luna, María Flavia., (2019) Paraburkholderia tropica as a plant-growth-promoting bacterium in barley: characterization of tissues colonization by culture-dependent and -independent techniques for use as an agronomic bioinput. Plant and Soil,

11. Ghosh, S., A. Qureshi and H.J. Purohit, (2019) D-Tryptophan governs biofilm formation rates and bacterial interaction in P. mendocina and S. aureus. Journal of Biosciences, 44(1).

12. Gideon Mamou,Ganesh Babu Malli Mohan,Alex Rouvinski,Alex Rosenberg,Sigal Ben-Yehuda., (2016)Early Developmental Program Shapes Colony Morphology in Bacteria. Cell Reports., 14(8): p. 1850-1857. 
13. Grzegorczyk, M., C. Restuccia and G. Cirvilleri, (2016) Biocontrol growth of Debaryomyces hansenii and Wickerhamomyces anomalus killer yeast strains against phytopatogenic fungi of the species Monilinia. New Biotechnology, 33: p. S209.

14. Hoang-Minh Nguyen, Mai-Lan Pham, Elena Maria Stelzer, Esther Plattner, Reingard Grabherr, Geir Mathiesen, Clemens K. Peterbauer, Dietmar Haltrich, Thu-Ha Nguyen,(2019) Constitutive expression and cell-surface display of a bacterial $\beta$-mannanase in Lactobacillus plantarum.. Microbial Cell Factories, 18(1)

15. Jia Liu,Yuan Sui,Michael Wisniewski,Samir Droby,Yongsheng Liu., (2013)Review: Utilization of antagonistic yeasts to manage postharvest fungal diseases of fruit, 167(2): p. 153-160.

16. Jing Xia, Jiaojiao Chen, Yuan Chen, Guoliang Qian, Fengquan Liu ,(2013) Type IV pilus biogenesis genes and their roles in biofilm formation in the biological control agent Lysobacter enzymogenes OH11. Appl Microbiol Biotechnol. Vol.102,(2), pp.833-846(14)

17. Jolivet-Gougeon, A. and M. Bonnaure-Mallet,(2014) Biofilms as a mechanism of bacterial resistance. Drug Discovery Today Technologies. 11: p. 49-56.

18. Junpeng Zhang,Weiying Li,Jiping Chen,Wanqi Qi,Feng Wang,Yanyan Zhou.,(2018)Impact of biofilm formation and detachment on the transmission of bacterial antibiotic resistance in drinking water distribution systems. Chemosphere Environmental Toxicology \& Risk Assessment,203:368-380

19. Klein, M.N. and K.C. Kupper, (2018) Biofilm production by Aureobasidium pullulans improves biocontrol against sour rot in citrus. Food Microbiology. 69(feb.): p. 1-10.

20. Laura Moyano, Analía Carrau, Silvana Petrocelli, Ivana Kraiselburd, Wolfgang Gärtner, Elena G. Orellano ,(2020) Bacteriophytochromes from Pseudomonas syringae pv. tomato DC3000 modulate the early stages of plant colonization during bacterial speck disease. European Journal of Plant Pathology, Vol.156 (11), pp.695-712.

21. Li Xu, Wensi Ying, Jiang Feng, Hu Huixin, (2015) Effects of interactions of auxin-producing bacteria and bacterial-feeding nematodes on regulation of peanut growths. PloS one, vol.10(4).

22. Maude Thérien,Heiko T. Kiesewalter,Emile Auria,Vincent Charron-Lamoureux,Mario Wibowo,Gergely Maróti,Ákos T. Kovács,Pascale B. ,Beauregard.(2020) Surfactin production is not essential for pellicle and root-associated biofilm development of Bacillus subtilis. Biofilm, vol.2

23. Masoud AđAbbas S T.,(2009)Evaluation of fluorescent pseudomonads for plant growth promotion, antifungal growth against Rhizoctonia solani on common bean, and biocontrol potential. Biological Control,48(2),0-107

24. Merle E Olson, Howard Ceri, Douglas W Morck, Andre G Buret, Ronald R Read, (2002),Biofilm bacteria: Formation and comparative susceptibility to antibiotics. Canadian Journal of Veterinary Research, 66(2): p. 86-92.

25. Michaela, C. , Joep, S. , Nag, K. H. , Griet, V. Z. , Marta, R. T. , \& Thevelein, J. M. (2014) Nutrient sensing and signaling in the yeast Saccharomyces cerevisiae. Fems Microbiology Reviews, (2): p. 2.

26. MinJia Chen.(2017),Research Development of Microbial Antagonists against Plant Disease. Advances in Microbiology, 6(2), 35-43(in Chinese) 
27. MIN Lijing, GUO Lu, YE Jianren,(2019) ,Mechanism of Burkholderia pyrrocinia JK-SH007 growthpromoting to plant via siderophore-mediation, 43(06):164-172.

28. Nunes-Alves and Cláudio,. (2014)Bacterial toxins:New weapons for plant colonization. Nature Reviews Microbiology,,12(9): p. 594-594.

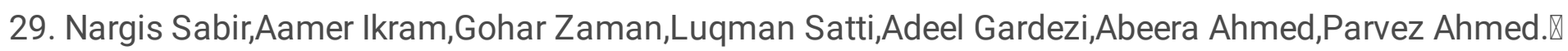
(2017) Bacterial biofilm-based catheter-associated urinary tract infections: Causative pathogens and antibiotic resistance. American Journal of Infection Control, p.खS0196655317306934.

30. Ren, J. H. , Ye, J. R. , Liu, H. , Xu, X. L. , \& Wu, X. Q. .(2011) Isolation and characterization of a new Burkholderia pyrrociniastrain JK-SH007 as a potential biocontrol agent. World Journal of Microbiology \& Biotechnology.,27(9): p. 2203-2215.

31. Ren, J. H. , Ye, J. R. , Liu, H. , Xu, X. L. , \& Wu, X. Q ,(2016)Influence of Burkholderia pyrrocinia JKSH007 on the Microbial Population and Functional Diversity of Microbial Communities in the Rhizosphere Soil of Poplar. Scientia Silvae Sinicae,(in Chinese)

32. Riahi, H., M. Hashemi and K. Sharifi, (2012)The effect of spent mushroom compost on Lecanicillium fungicola in vivo and in vitro. Archives of Phytopathology \& Plant Protection. 45(17): p. 2120-2131.

33. Sauer, K., Anne K, Camper, Garth D, Ehrlich, J William, Costerton, David G, Davies. (2002)Pseudomonas aeruginosa Displays Multiple Phenotypes during Development as a Biofilm. Journal of Bacteriology, 184(4): p. 1140-1154.

34. Schembri, M.A., K. Kjærgaard and P. Klemm, (2003),Global gene expression in Escherichia coli biofilms. Molecular Microbiology, 48(1).

35. Tantan Gao,Jennifer Greenwich,Yan Li, Qi Wang, Yun rong Chai,(2015),The Bacterial Tyrosine Kinase Activator TkmA Contributes to Biofilm Formation Largely Independently of the Cognate Kinase PtkA in Bacillus subtilis. 197(21): p. 3421.

36. Theresa Klein,David Zihlmann,Nicolas Derlon,Carl Isaacson,Ilona Szivak,David G. Weissbrodt,Wouter Pronk,.(2016).Biological control of biofilms on membranes by metazoans,88: p. 20-29.

37. Wangxiang Zhang, Junjun Fan, Qianqian Tan, Mingming Zhao, Ting Zhou.(2017),The effects of exogenous hormones on rooting process and the activities of key enzymes of Malus hupehensis stem cuttings. Plos One, 12(2): p. e0172320.

38. Wan-Hui,Liu;Fei-Fei,Chen;Chao-En,Wang;Huan-Huan,Fu;Xue-Qi,Fang;Jian-Ren,Ye;Ji-Yuan , (2019)Shilndole-3-Acetic Acid in Burkholderia pyrrocinia JK-SH007: Enzymatic Identification of the Indole-3-Acetamide Synthesis Pathway. Frontiers in Microbiology,Vol.10

39. Wenyan Cui,Pengjie He,Shahzad Munir,Pengbo He,Xingyu Li,Yongmei Li,Junjie Wu,Yixin Wu,Lijuan Yang,Pengfei He,Yueqiu He. ,(2019) Efficacy of plant growth promoting bacteria Bacillus amyloliquefaciens B9601-Y2 for biocontrol of southern corn leaf blight. Biological Control, 139.

40. Wiyono, S., D.F. Schulz and G.A. Wolf, (2008)Improvement of the formulation and antagonistic growth of Pseudomonas fluorescens B5 through selective additives in the pelleting process. Biological Control., 46(3): p. 0-357. 
41. Xu, L., Y. Pan and F. Yu, (2015)Effects of water-stress on growth and physiological changes in Pterocarya stenoptera seedlings. Scientia Horticulturae. 190: p. 11-23.

42. Xianling, J, Guobing, L, Yingping, G, Chengchao, Z, \& Zhimei, M.,(2008)Biological control against bacterial wilt and colonization of mulberry by an endophytic Bacillus subtilis strain\&nbsp. Fems Microbiology Ecology. 65(3): p. 565-573.

43. YunWang,Yulin Li, Weidong Xu,Xiangfeng Zhen, Xiaoyun Zhang, (2018)MardourH,Abdellhai, Lina Zhao,Huifang Li, Junwei Diao, HongXin Zhang,Exploring the effect of $\beta$-glucan on the biocontrol growth of Cryptococcus podzolicus against postharvest decay of apples and the possible mechanisms involved. Biological Control,121: p. 14-22.

44. Zhou, Xiaohong Zheng, Renhua Liu, Guangxin Yang, Xu Zhou, Yanwei Thomas, Laux Yan, Zhen Harding, Scott A Shi, Jisen Chen, Jinhui ,(2017),Desiccation Treatment and Endogenous IAA Levels Are Key Factors Influencing High Frequency Somatic Embryogenesis in Cunninghamia lanceolata (Lamb.) Hook. Frontiers in Plant Science, 8: p. 2054-.

\section{Figures}
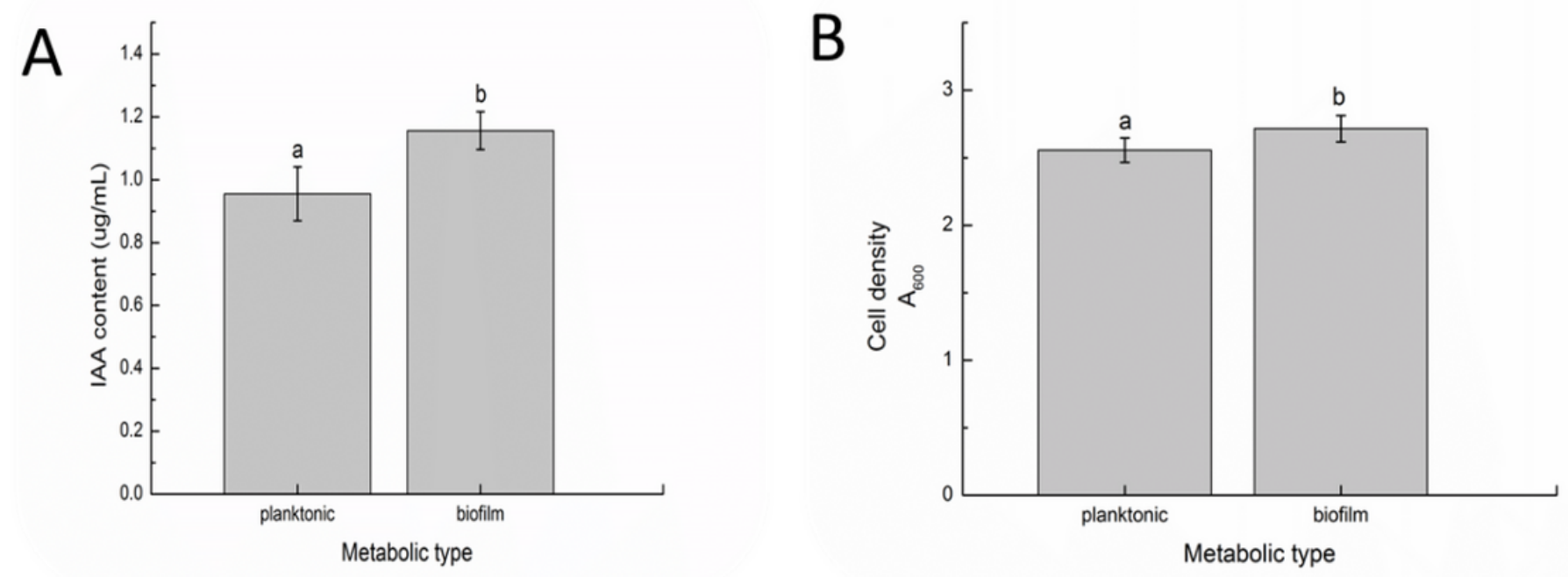

\section{Figure 1}

The effect of nutrient addition on JK-SH007 growth and metabolism Note: (A) Contrast in the secreted IAA concentration between two forms of JK-SH007. (B) Contrast in growth limit of JK-SH007 between two forms. Each experiment was performed at least three times in triplicate. Error bars represent the standard error of the mean. Different lowercase letters indicate significant differences.) (Pख0.05) 
A.

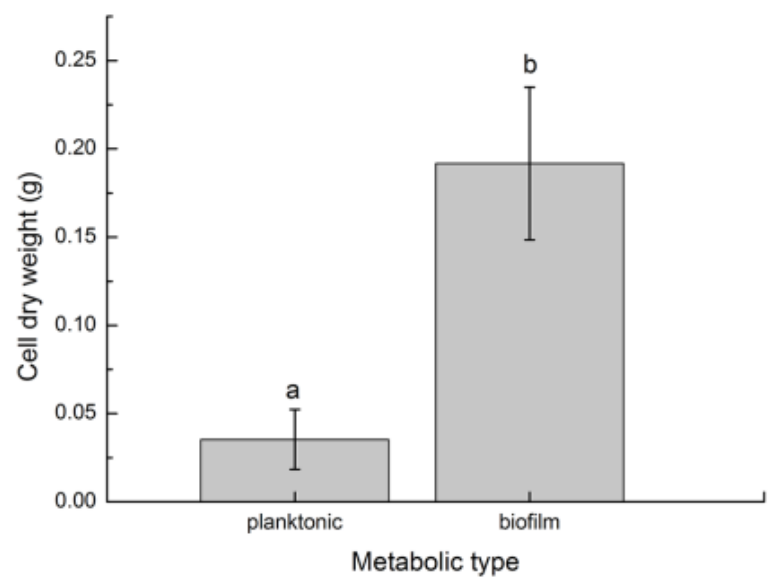

C.

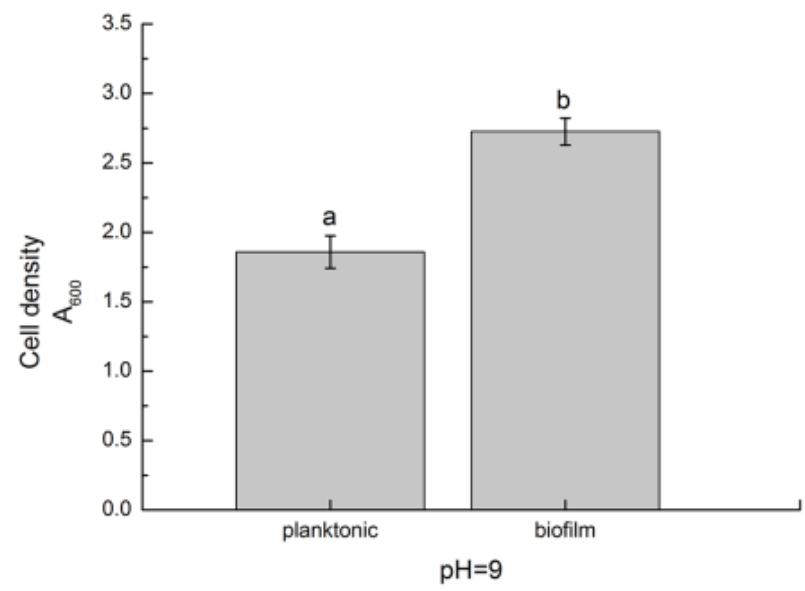

B.

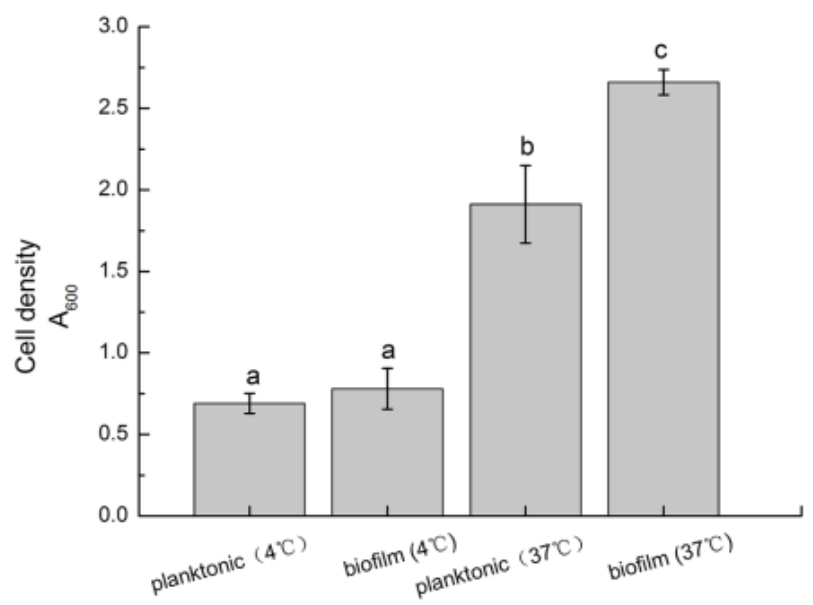

D.

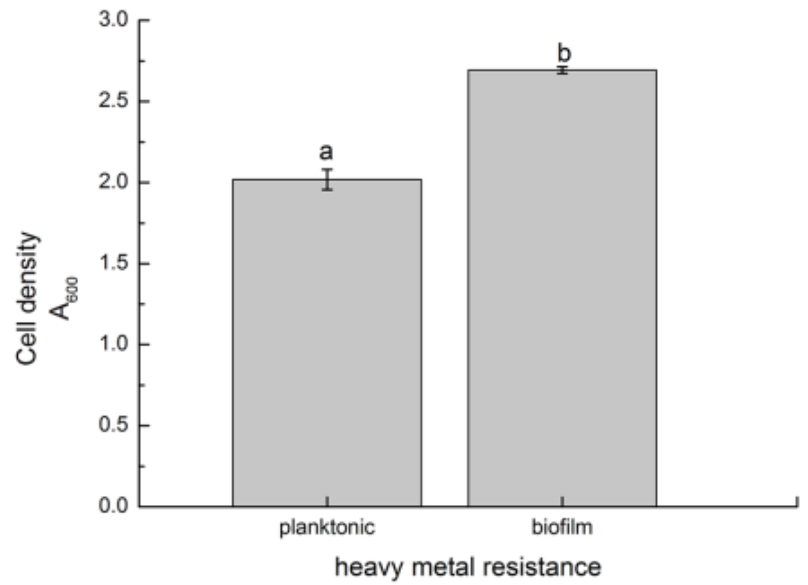

\section{Figure 2}

Effects of nutrient source on the growth and stress resistance of JK-SH007 Note: (A) The two metabolic fermentation broths were centrifuged to obtain bacterial cells, and the dry weights of the cells were compared after drying; (B) comparison of the growth of the two forms of JK-SH007 under temperature stress; (C) comparison of growth of the two forms of JK-SH007 in an alkaline environment; and (D) comparison of growth of the two forms of JK-SH007 in a high-Cu2+ environment. Each experiment was 
performed at least three times in triplicate. Error bars represent the standard error of the mean. Different lowercase letters indicate significant differences. (Pख0.05)

A.

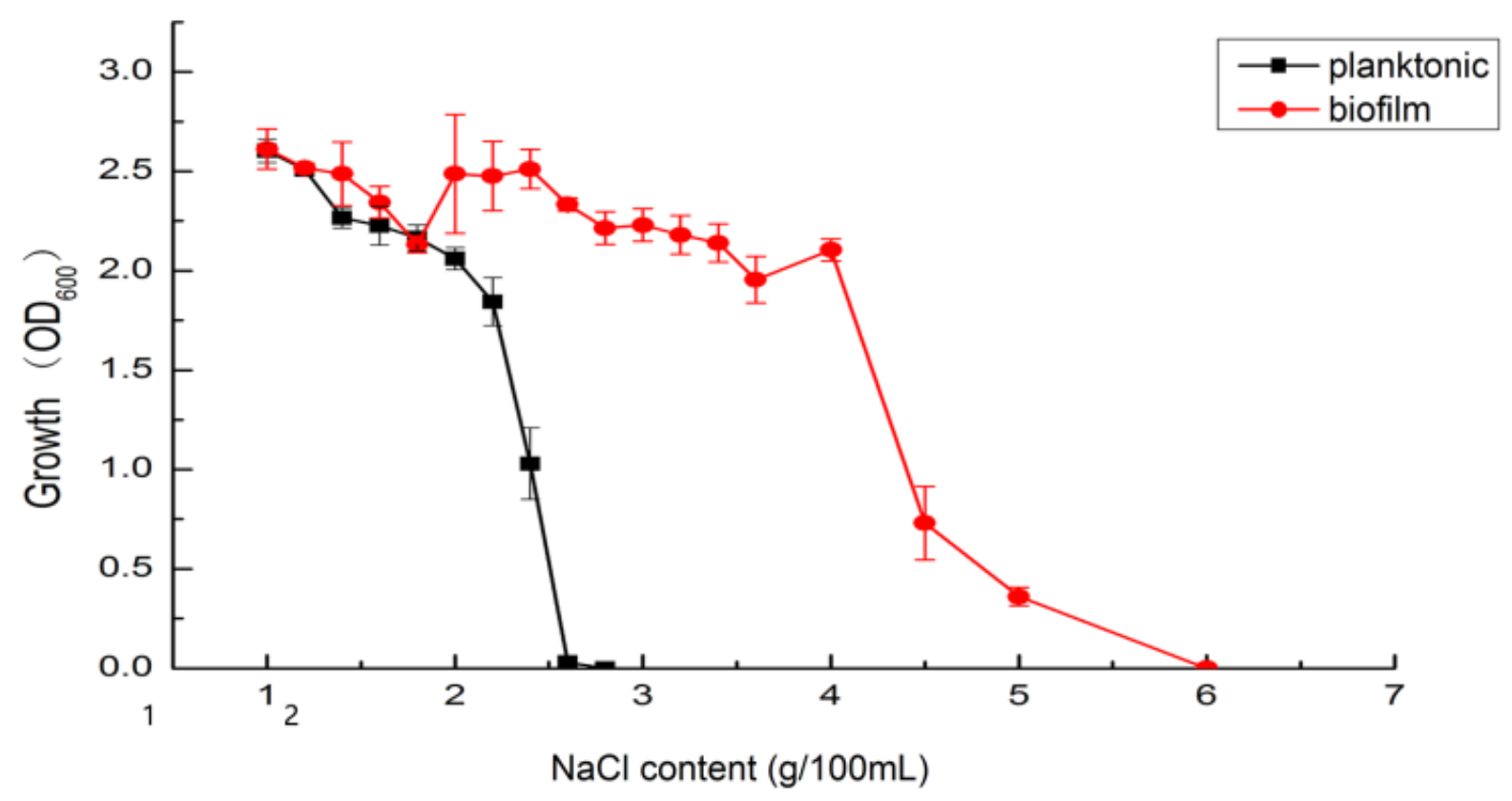

B.

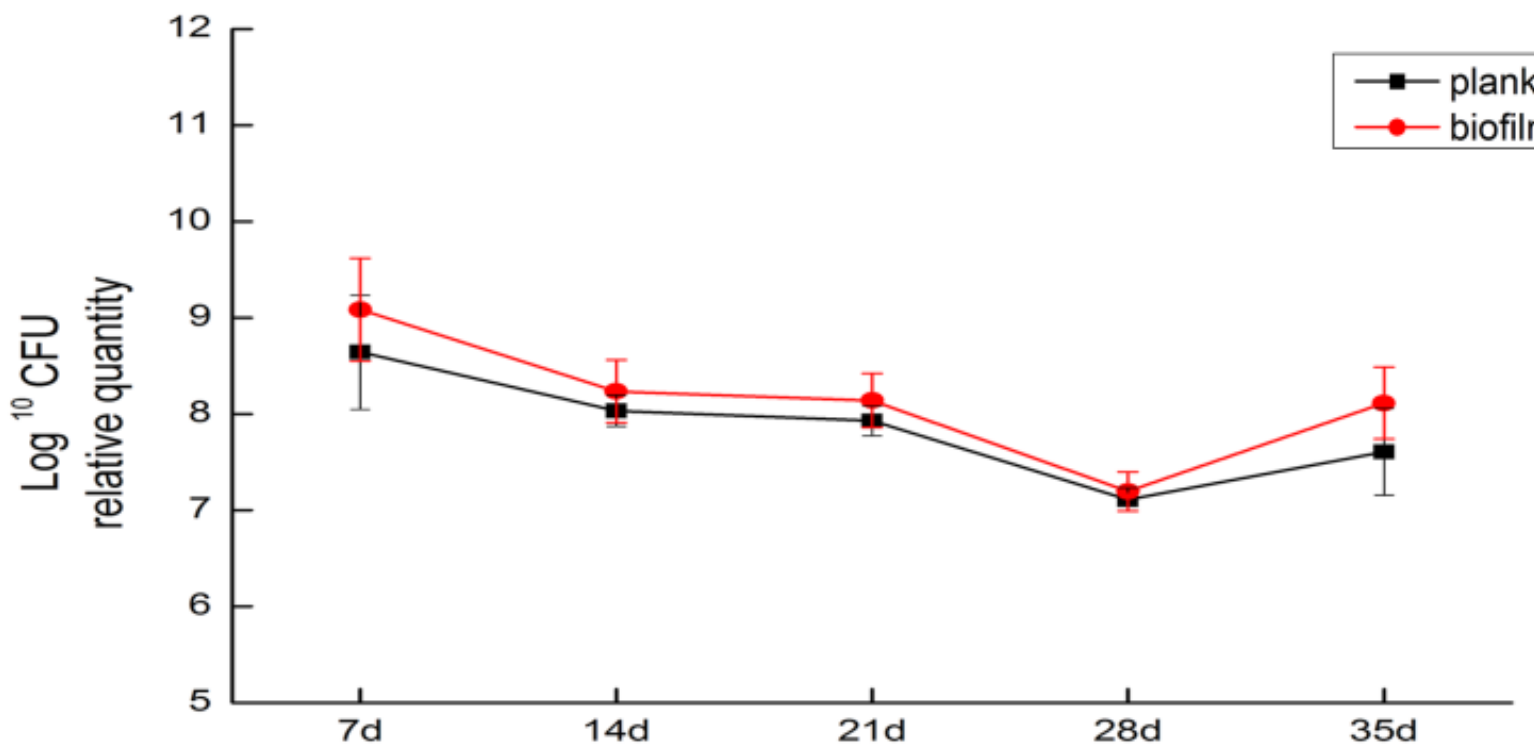

incubation time

\section{Figure 3}

The effect of adding nutrient sources on the growth and colonization ability of JK-SH007 Note: (A) the two types of cells in fermentation broth were added at $1 \%$ to LB media with different $\mathrm{Na}+$ concentrations for $48 \mathrm{~h}$, and the cell density was compared. (B) The relative colonization numbers of the two forms of JK-SH007 cells in poplars were collected every other week for a week. Each experiment was performed at 
least three times in triplicate. Error bars represent the standard error of the mean. Different lowercase letters indicate significant differences. (P凶0.05)
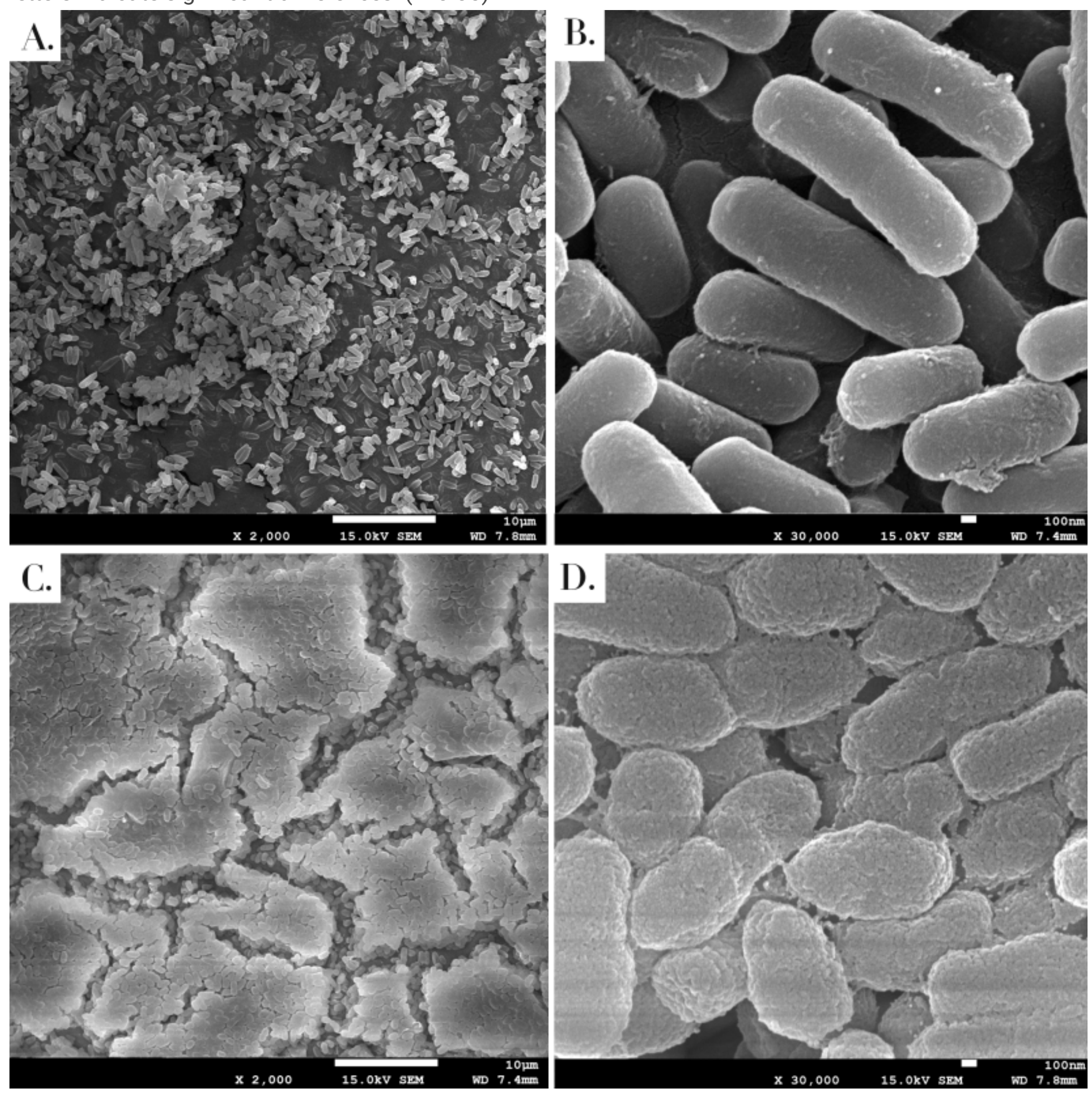

Figure 4

Electron microscope photos of JK-SH007 grown in medium with or without additional nutrients Note: (A) The surface of a JK-SH007 colony in the planktonic state at 2000x; (B) the surface of single cells of planktonic JK-SH007 at 30,000x; (C) the surface of a colony of JK-SH007 biofilm at 2000x; and (D) the surface of a single colony of JK-SH007 biofilm at 30,000x. 


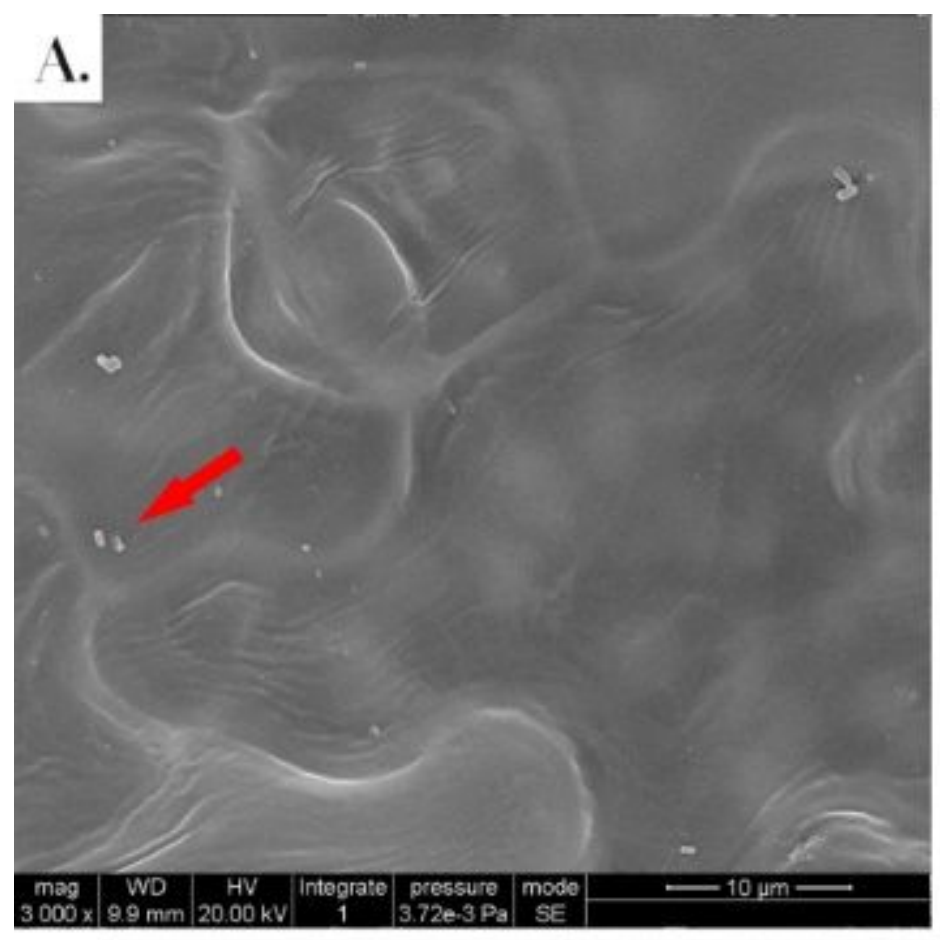

B.
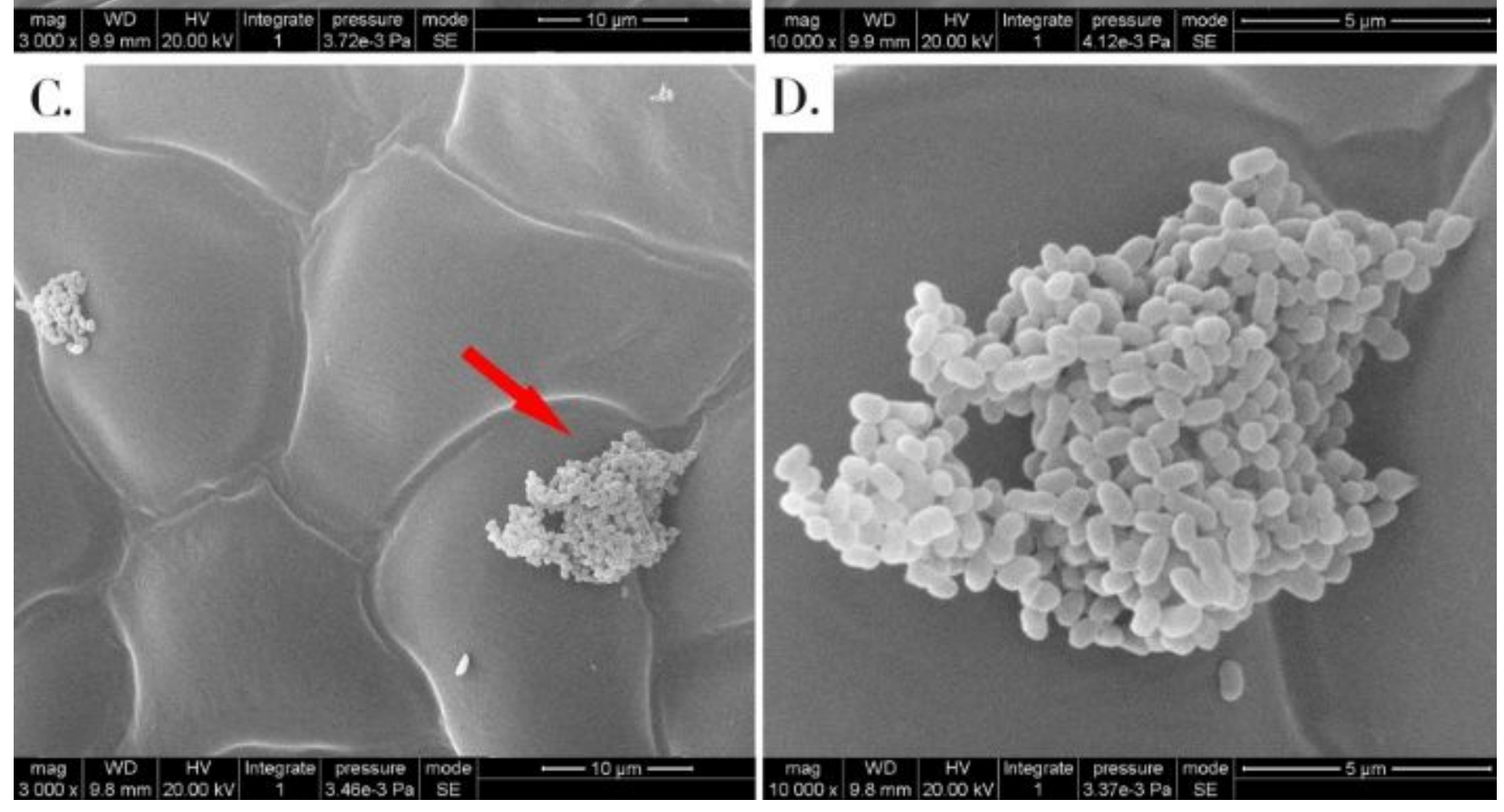

\section{D.}

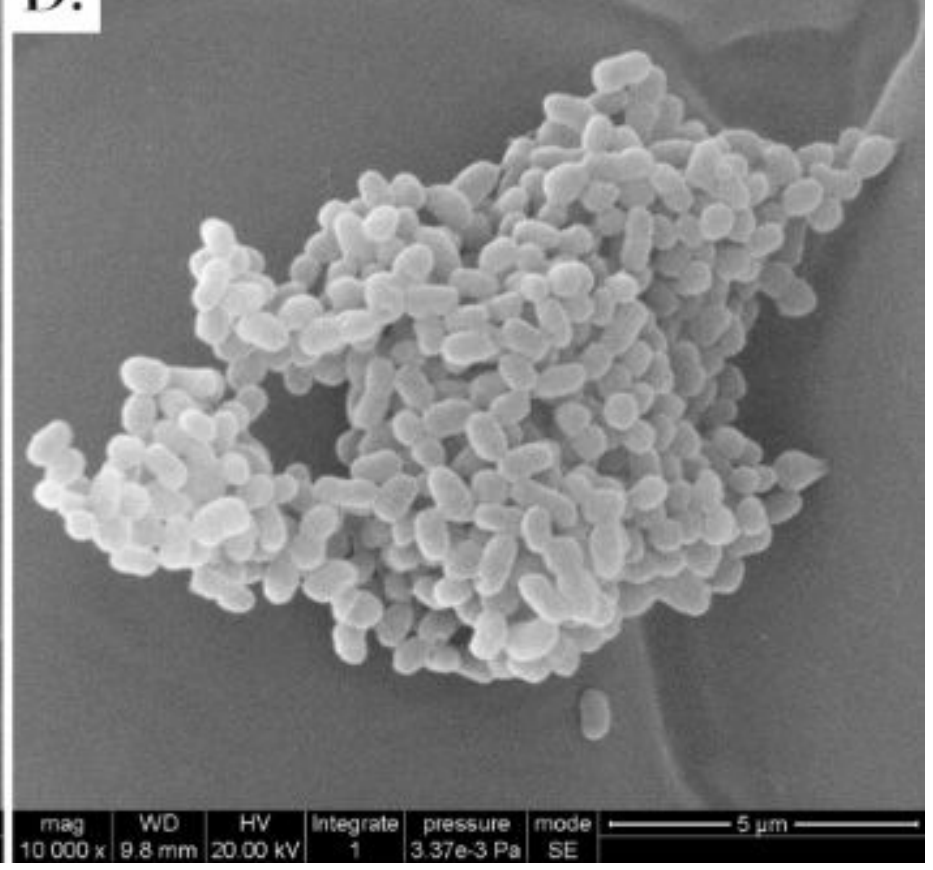

Figure 5

Electron micrograph of planktonic and biofilm JK-SH007 colonized on poplar Note:(A) JK-SH007 grown without added nutrients colonized around the leaves of the poplar (3000x), and (B) JK-SH007 grown without added nutrients colonized around the leaves (10,000x). (C) JK-SH007 grown with added nutrients colonized around the leaves (3000x), and (D) JK-SH007 grown with added nutrients colonized the details around the leaves $(10000 \times)$. Arrows indicate that $(\mathrm{A}) \mathrm{JK}-\mathrm{SH} 007$ is attached as single colonies to poplar leaf tissues and that (C) a cell cluster structure was formed by JK-SH007 on poplar leaf tissue. 


\section{JK-SH007}
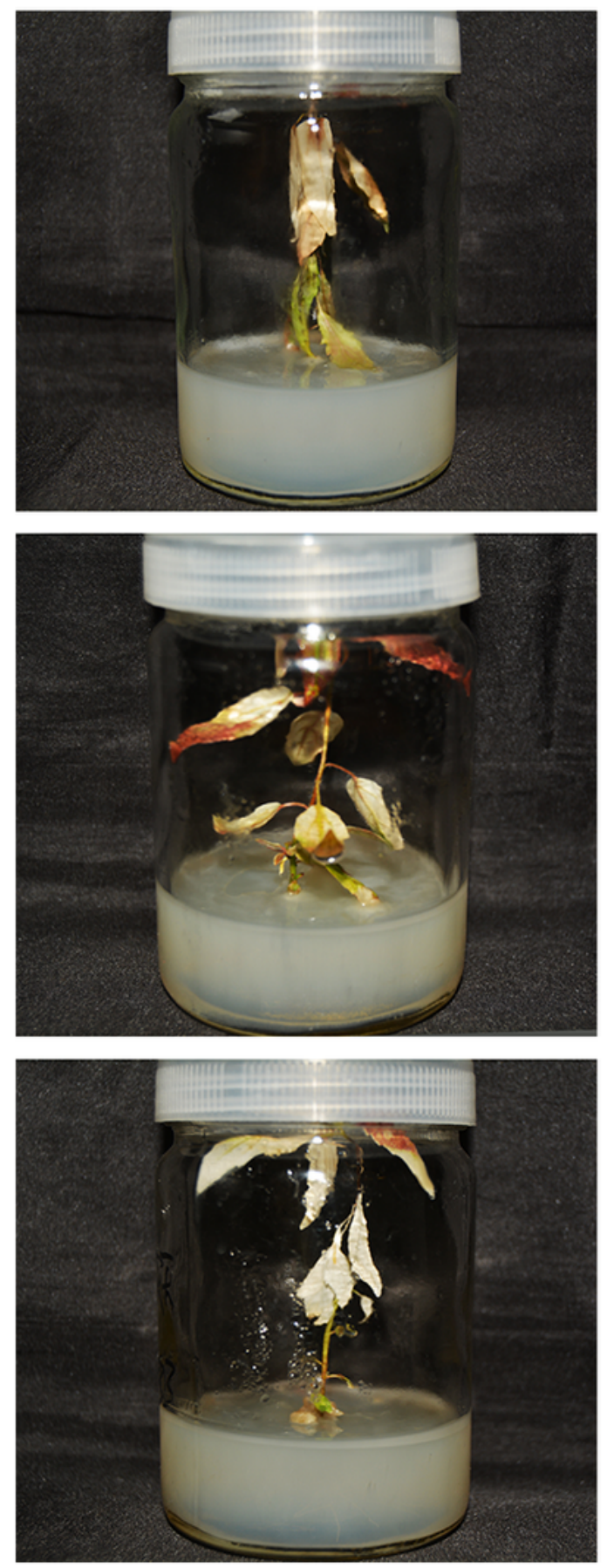

\section{JK-SH007 (BF)}
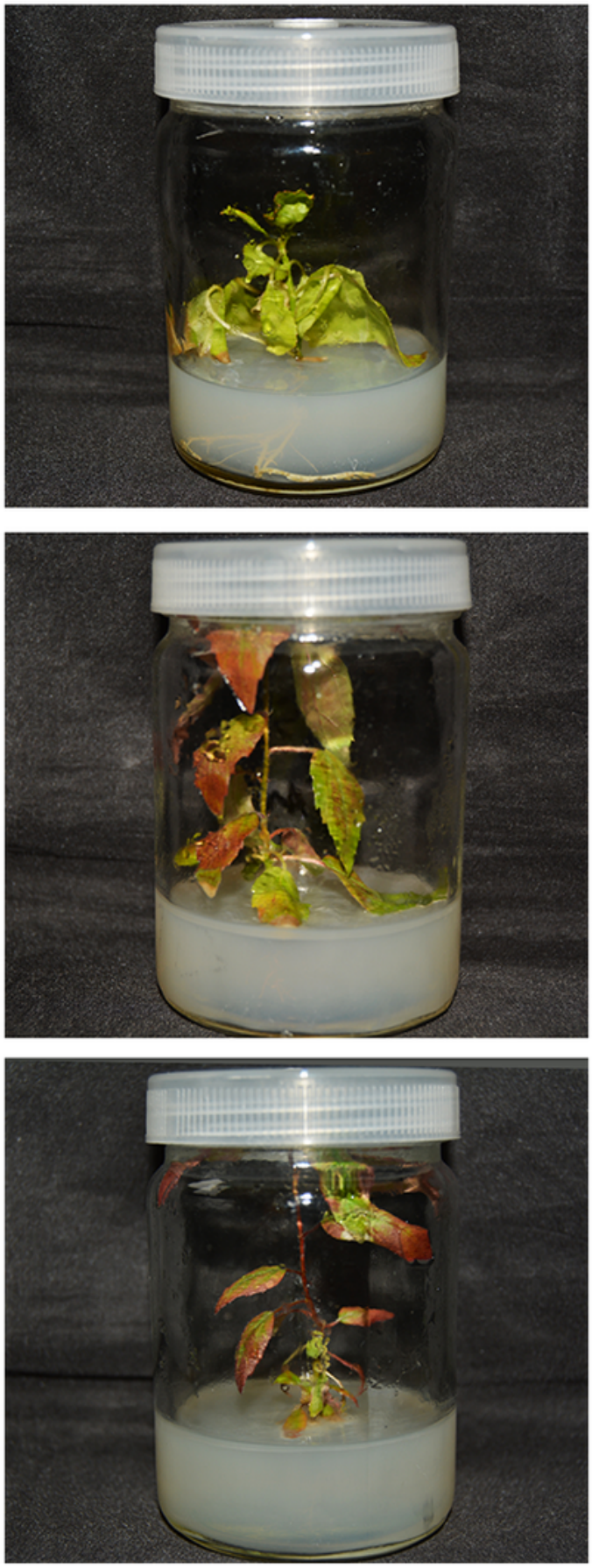

\section{Figure 6}

Effects of JK-SH007 metabolites on poplar Note: The left picture shows the growth of poplar seedlings inoculated with planktonic JK-SH007 metabolic fluid; the right picture shows the growth of poplar seedlings inoculated with metabolic fluid from biofilm JK-SH007. 

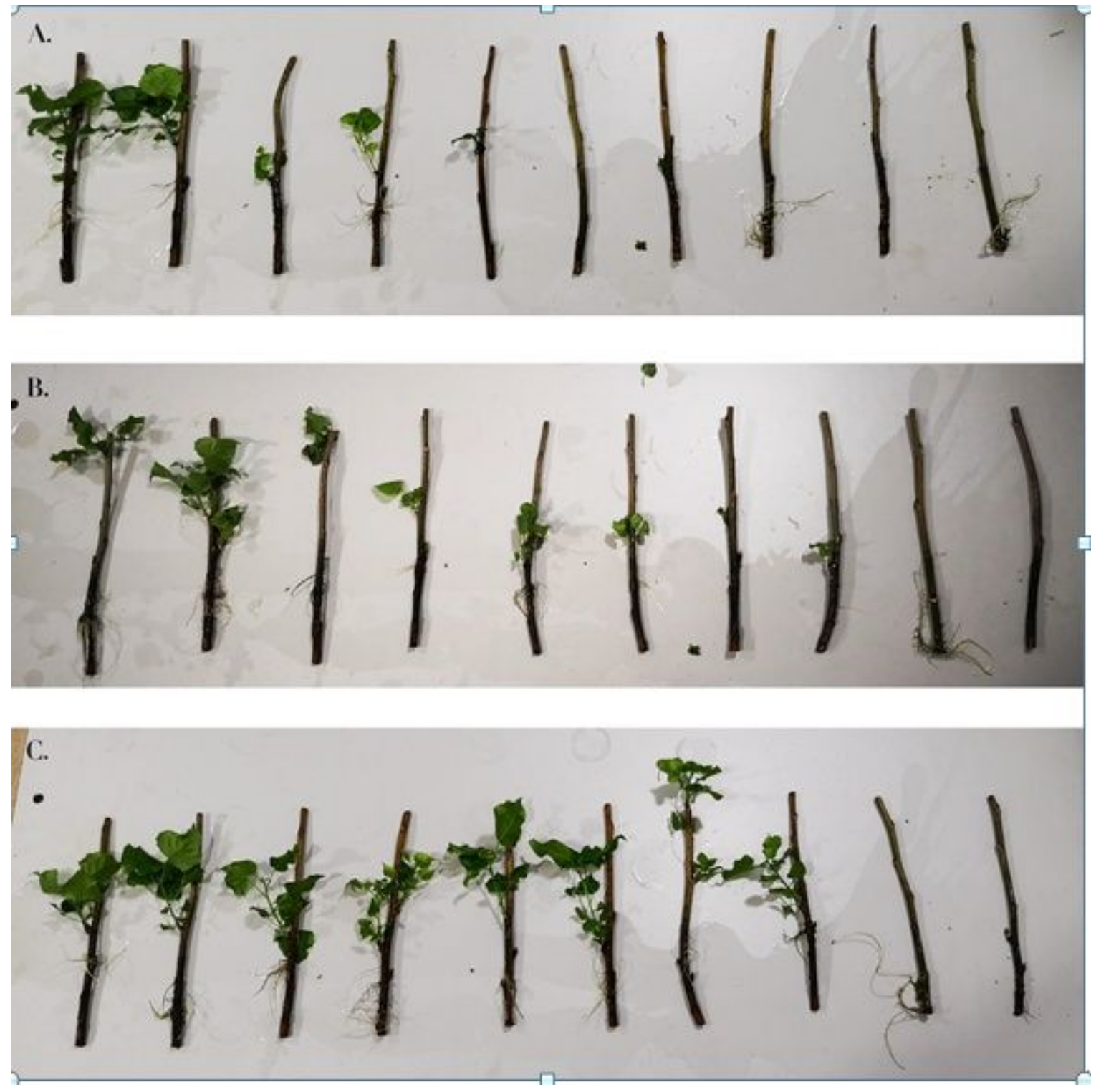

Figure 7

JK-SH007 effect on the growth of poplar branches Note: (A) Sterile water control group, the germination and promotion ability of poplar branches in Hoagland nutrient solution; (B) the effect of inoculation with planktonic JK-SH007 in hydroponic solution on the germination and development of poplar branches; and (C) inoculation with biofilm JK-SH007 in hydroponic solution has an effect on the germination and development of poplar branches. 